\title{
Boscán ante Petrarca. \\ El proyecto de un cancionero imposible
}

\author{
Matteo Lefêvre \\ Universidad de Roma «Tor Vergata» \\ matteo.lefevre@libero.it
}

Recepción: 10/05/2013, Aceptación: 01/10/2013, Publicación: 20/12/2013

\begin{abstract}
Resumen
El presente artículo está dedicado a analizar los poemas que forman parte del «Libro II» de las Obras de Boscán y algunas de Garcilaso de la Vega (Barcelona, Carles Amoros, 1543) según una perspectiva ética y axiológica conforme a Rerum Vulgarium Fragmenta. A partir de esta amplia sección, en efecto, Boscán propone su poesía «a la manera italiana», es decir, a la manera de Francesco Petrarca, sin embargo su cancionero amoroso se mantiene bastante lejos del compromiso espiritual que envuelve la lírica del autor toscano. En particular, a la imitatio styli no parece corresponder la imitatio vitae, y el poeta espańol se limita a reproducir, del cancionero petrarquesco, sólo ciertos rasgos formales y estilísticos, algunas situaciones convencionales y determinados motivos literarios, sin adherirse a la fuerte estructura moral de $R V F$, que en cambio culmina en la conversión del poeta y en la retractación de cualquier tipo de amor terrenal en nombre del ideal cristiano.
\end{abstract}

Palabras clave

Boscán; Petrarca; Cancionero; Petrarquismo español; Poesia s. xvı; Lírica imperial; Imitación poética; Poesía del Renacimiento español

\begin{abstract}
Boscán before Petrarch. The project of an impossible canzoniere

In this article we analyse Boscán's poems contained in «Libro II» (Second Book) of the Obras de Boscán y algunas de Garcilaso de la Vega (Barcelona, Carles Amoros, 1543) throughout an ethical and spiritual point of view, as well as it stands out in Petrarch's Rerum Vulgarium Fragmenta. In this part of his cancionero, Boscán imitates the italian Poet, but his poems in their combination are far enough from Petrarch's spiritual perspective. In particular, imitatio styli doesn't match with imitatio vitae, and the spanish poet only reproduces formal and stylistic features as well as some literary motives of petrarchan Canzoniere, without really endorsing $R V F$ moral structure, that culminates with the christian conversion of the poet and the abandonment of secular love.
\end{abstract}

\section{Keywords}

Boscán; Petrarca; Cancionero; Spanish Petrarchism; 16th century Spanish Poetry; Imperial Lyric; Poetical Imitation; Spanish Renaissance Poetry 
Las Obras de Boscán y Garcilaso (Barcelona, Carles Amorós, 1543) constituyen un punto de referencia esencial para examinar los códigos de la comunicación lírica entre Italia y Espańa en el Cinquecento, y más aún si esto se observa a la luz de un movimiento literario internacional —el petrarquismo- que en el mundo hispánico cambió radicalmente la manera de hacer poesía y hasta de ser poeta. Si se abarca el tema del petrarquismo, de hecho, hay que tener en cuenta problemas de poética y política cultural, de teoría literaria y ritos sociales, de compromiso ético y estético. Y, obviamente, cabe hacer hincapié en la heurística y la hermenéutica de la imitación, es decir, en la aproximación y la postura que los poetas españoles, así como los italianos, adoptaron ante el modelo de Petrarca principalmente a lo largo de los siglos XV y XVI.

En particular, en relación a la primera fase de la admiración petrarquesca que se documenta en Italia, Antonio Gargano ha subrayado la existencia y la consistencia de un "petrarquismo sin Petrarca», ${ }^{1}$ que arraiga y prolifera en las décadas iniciales del Renacimiento y precede cronológicamente al petrarquismo 'ortodoxo', desarrollado a nivel teórico y en la praxis lírica por Pietro Bembo, en las primeras décadas del XVI, con la publicación de las Prose della volgar lingua (1525) y de las Rime (1530). El petrarquismo italiano del siglo xv y de comienzos del XVI - y algo parecido puede observarse también en los poetas castellanos presentes en las primeras ediciones del Cancionero general - aún encarna una imitación 'des-compuesta', ecléctica e irregular de Petrarca; sin embargo, al mismo tiempo remite a ese nexo ideológico que se estableció en la época renacentista entre poesía, sociedad y política cortesanas que, a la vez, unas décadas después sería una clave importante para la difusión y la promoción de la lírica «a la manera italiana» en la Espańa imperial. En efecto, con el advenimiento de los Austrias y la afirmación del dominio hispánico en Europa, a pesar de una situación geopolítica muy distinta a la del xv tanto en Italia como en España - Baldassar Castiglione ofrece un testimonio nostálgico e inequívoco de la situación en su Cortegiano (1528), con prontitud traducido y publicado en castellano por el propio Boscán en $1534^{3}$ — , precisamente la 'mitología' cortesana y la petrarquesca constituyen el eje ideológico, vivencial y poético en torno al cual se edifica el clasicismo quinientista, cuyos primeros intérpretes castellanos sueñan con emular a los poetas del Renacimiento itálico y se distancian progresivamente de la mentalidad foral y de la tradición cancioneril. ${ }^{4}$ En la época de

1. Gargano (2005: 51).

2. Recuérdese, al respecto, el ensayo de Rico (1987: 230 y ss.).

3. Los quatro libros del cortesano compuestos en italiano por el conde Balthasar castellon, y agora nueuamente traduzidos en lengua castellana por Boscan, Barcelona, Pedro Monpezat, 1534. Sobre la importancia de la 'doctrina' cortesana en el panorama europeo del XVI, cf. sobre todo GuIDI (1973 y 1978); Ossola-Prosperi (1980: II); BurKe (1995) y QUONDAM (2000).

4. A esta visión cultural e incluso 'ideológica' del petrarquismo ibérico en los últimos años se ha dedicado principalmente la academia americana. Cf. Lorenzo (2007) y MiddLebrook (2009). 
Carlos V política y poética parecen moverse al mismo ritmo y ambas adquieren una perspectiva supranacional: tanto los fragmenta del Imperio como los de la lírica románica conocen una sistemática reductio ad unum que lleva al César y al autor del Canzoniere a encarnar una referencia ideológica y cultural y un modelo ético ineludible para más de una generación de poetas, soldados, diplomáticos y mandatarios de media Europa. En este contexto, la hermenéutica bembiana sobre el texto petrarquesco 'extremó' la situación: radicalizando la imitación del Maestro e insistiendo en la coincidencia rigurosa entre imitatio styli e imitatio vitae, el autor de las Prose trataba asuntos literarios y a la vez espirituales, éticos y estéticos. Asimismo, sobre todo en los años siguientes a la coronación de 1530, que de hecho recomponía las divergencias políticas entre el Papa y el Emperador culminadas en el Sacco di Roma (1527), el petrarquismo encarnaba un modus scribendi - et vivendi - muy bien aceptado en la Corte y en la Curia, ya que, en el plano moral, en la poesía de Petrarca interpretada iuxta propria principia destacaban elementos que reconducían al providencial apaciguamiento de las pasiones y las discordias, y se reafirmaban principios de equilibrio y orden que podían enderezarse tanto en dirección religiosa como rigurosamente política.

De todas maneras, la versatilidad del petrarquismo, independientemente de la visión de Bembo o de cualquier otro comentarista, justo en las décadas centrales del xvi fue captada con prontitud y esmero por los poetas italianos y españoles, que utilizaron motivos y metros, lengua y retórica de Rerum Vulgarium Fragmenta para enfrentarse a distintos argumentos y campos temáticos, del amor a la amistad, del encomio al anatema. Petrarca, más que un autor, se hace un estilo, ${ }^{5}$ un "palimpsesto"; es un mito distante y a la vez una fuente asequible, modelo de una casuística relativa a la práctica poética —es decir, temática, estilística y rítmica - y de un itinerario espiritual, paradigma de los trastornos y los desvaríos del alma humana, así como de la redención cristiana.

En el caso de Boscán, la imitación petrarquesca se concibe, se desarrolla y se define con respecto a toda esta serie de factores, que, como hemos visto, abarcan el discurso estrictamente literario, junto al ideológico, al social y al ético. ${ }^{6}$ En lo que concierne al primer aspecto, su pasión por el humanismo renacentista y por la literatura italiana responde a la 'modernidad' de su formación ${ }^{7}$ y de su tiempo, confirman su deseo de adherirse a una visión poética y cultural nueva. A pesar de que en su lírica es fuerte la influencia de ciertos modelos y esquemas tradicionales, del conceptismo verboso típico de la poesía cancioneril y del petrarquismo italiano prebembesco, así como de Ausiàs March y otros poetas coterráneos suyos, ${ }^{8}$ no cabe duda de que Boscán, por lo menos a partir de la segunda mitad

5. Cf. Erspamer (1987b: 466).

6. A este respecto, en este artículo se desarrollan y en parte revisan algunas tesis de LEFÈVRE (2006: 113-139).

7. Cf. Riquer (1945: 30).
8. Sobre el tema, en particular sobre la estricta relación que hay a nivel estructural entre el 'cancionero' de Boscán y el de Ausiàs March, véase Morros (2005). 
de los años veinte - el encuentro con Navagero seguramente es un pretexto, un topos humanístico, pero sigue siendo una referencia cronológica muy útil-, ya empieza a mirar hacia adelante, hacia nuevos ritmos y nuevos rumbos. Estamos en los albores del petrarquismo español, y justamente la poética y, sobre todo, la poesía de Boscán aún oscila entre polos y fuerzas de atracción diferentes.

La aceptación del petrarquismo y de la cultura renacentista, además, como decíamos, no es sólo una opción literaria, sino también una elección 'ideológica'; es la asunción de una época nueva desde un punto de vista histórico, que naturalmente envuelve también la función y la difusión de la literatura. Ya no es tiempo de castillos aislados y príncipes solitarios y orgullosos, encerrados entre sus manuscritos y sus boni autores, ya no hay fronteras nacionales y barreras lingüísticas tan marcadas como antes. La misma versión que Boscán realiza del tratado de Castiglione lo demuestra tanto por razones lingüísticas y estilísticas como por la adopción consciente de la "forma del vivere» y de los 'preceptos' de la cortesanía, y encaja perfectamente en su camino de emancipación no sólo artística, sino también política y social, según requería el Renacimiento. ${ }^{9} Y$ mientras el mundo conocido y el Imperio hispánico se amplían cada día más gracias a las conquistas de Carlos V, otro 'imperio' aún más duradero y poderoso —el de la imprenta - hace que los libros circulen de manera más rápida, que la práctica literaria, y poética en particular, no esté reservada sólo a una minoría selecta, sino que cumpla sus requisitos y su papel 'cortesanos' y sirva como instrumento de relación interpersonal, de intercambio intelectual y hasta económico. En la época de Boscán, y hasta la publicación de los primeros Índices de libros prohibidos, las ideas literarias, filosóficas, políticas y religiosas gracias al boom de la imprenta flotan libremente en los territorios europeos; y en el mundo hispanoitaliano esto repercutió también notablemente en la primera teorización, producción y difusión del petrarquismo, ya que los libri di rime, al interior de los dominios imperiales, viajan rápidamente de una corte y de una nación a otra.

Corolario de todo esto es también el compromiso ético que se desprende de la asunción del modelo petrarquesco. El sistema del Canzoniere supone, en primer lugar, tanto en los poetas italianos como en los primeros petrarquistas españoles, la difícil tarea de acomodar la exposición inmediata de la propia vicisitud existencial con los contraintes del espécimen, la casuística lírica y biográfica - y poco importa que esa fuera real o ideal, literaria - con la estructura rigurosa y radical de Rerum vulgarium fragmenta, cuyo itinerario espiritual exigía un principio, un fin y unas etapas intermedias bien determinadas. En este sentido, hay que valorar apropiadamente la relación que se establece entre Boscán y la 'ortodoxia' de la obra petrarquesca: más que una cuestión de género, de categorías macrotextuales que aplicar a la producción lírica del poeta español —a este 
respecto, tiene un sentido relativo identificar su obra como "cancionero petrarquista» o, más libremente, como "cancionero de autor» ${ }^{10}$ - lo que sí importa es poner a prueba su postura ante el modelo, su «autoconciencia poética», ${ }^{11} \mathrm{su}$ relación con el universo temático, retórico y moral del Canzoniere.

Si se analiza la estructura micro- y macrotextual del «Libro II» (XXIXCXXX) en la óptica del petrarquismo crítico, como es sabido, algunas composiciones de esta amplia sección participan realmente en la reconstrucción de un camino existencial, de una particular isotopia, e invitan a leer todo el libro como un cancionero. ${ }^{12}$ En la silloge de Boscán varios poemas describen y evocan los episodios amorosos según una perspectiva pseudo-narrativa y en ciertos casos desempeñan propiamente funciones de prólogo y epílogo respecto a todo el conjunto, contribuyendo a diseñar una parábola poética y personal al modo del texto petrarquesco. El proyecto de autor, configurado sobre la experiencia lírica del poeta italiano tanto en la forma (imitatio styli) como en el contenido y sus implicaciones espirituales (imitatio vitae), intenta englobar, por lo tanto, algunos elementos que permiten observar la presencia de un plan predefinido en su estructura cíclica y edificante; en la poesía de Boscán, más que en los calcos o en las referencias más o menos directas a los versos petrarquescos, el problema de la imitación reside sobre todo en la relación con la axiología del Canzoniere, con el compromiso ético, además de literario, de un libro que durante siglos representó el hipotexto de la tradición lírica occidental así como el vademecum de la experiencia erótica, moral e intelectual de todo hombre de letras.

En el sistema petrarquista, pues, es la composición de apertura la que cumple casi siempre la función de encuadrar un cancionero dentro del sistema mismo, sobre todo por su semejanza con el primer soneto de $R V F$ tanto en el contenido y como en el estilo. ${ }^{13}$ En este sentido, a la hora de dar comienzo al "Libro II», Boscán se sitúa inmediatamente en el cauce de la tradición italiana -a lo largo del eje Petrarca-Bembo- y para introducir su producción «al itálico modo» elige un poema como exordio en el que destacan elementos que enmarcan la lírica de nuestro autor dentro de un proyecto unitario al estilo petrarquista.

10. Cf. Burguillo López (2008).

11. Cf. Ruiz Pérez (2009). El mismo Ruiz Pérez coloca al poeta entre los extremos de «Narciso y Proteo", pues, en sus Obras, por un lado, asume la mirada retrospectiva y supuestamente autobiográfica a la manera del Canzoniere, por otro, también modula la imitación petrarquesca a la luz de los nuevos géneros y gustos renacentistas procedentes de Italia («Libro III»). Cf. Ruiz Pérez (2007).

12. Respecto a la cuestiones teóricas correspondientes a la definición de "macrotexto», véanse, en primer lugar, SEgRe (1969) y CoRTI (1974).
En cuanto al ámbito específico de la poesía lírica, cf. sobre todo GENOT (1967), de interés general y teórico; LoNGHI (1979), donde la autora hace referencia a la coherencia textual como elemento discriminador entre un cancionero propiamente dicho y una más general y 'desarticulada' raccolta de poemas; Santagata (1979: 10-56), donde el estudioso demuestra creer, de modo menos integralista en el cancionero como género fluido; Gorni (1989); y Cappello (1998: 13-14). Para el caso español, cf. sobre todo Prieto (1986) y, últimamente, Burguillo López (2008).

13. ERsPamer (1987a: 110). 
Nunca d'Amor estuve tan contento que en su loor mis versos ocupase; ni a nadie consejé que s’engañase buscando en el amor contentamiento. Esto siempre juzgó mi entendimiento: que d'este mal tod'hombre se guardase, y así, porque'sta ley se conservase, holgué de ser a todos escarmiento. !O vosostros que andáis tras mis escritos gustando de leer tormentos tristes, según que por amar son infinitos!, mis versos son deziros. «! $\mathrm{O}$ benditos los que de Dios tan gran merced huvistes que del poder d'Amor fuésedes quitos!» ${ }^{14}$

En el primer terceto, la alusión a $R V F$ I es explícita: ${ }^{15}$ desde un punto de vista temático y autoanalítico, se reproduce la postura retrospectiva del sonetoprólogo petrarquesco, y, por lo que atañe al léxico, el apóstrofe al lector alude abiertamente al incipit del poeta italiano:

!O vosostros que andáis tras mis escritos

Voi ch'ascoltate in rime sparse il suono

La actitud del autor español confirma la opinión de Erspamer, para quien —aparte de los calcos más evidentes y casi descarados - en el sistema del petrarquismo, el vector más fácil está constituido por el «camino alternativo [...] del paradigma léxico», según el cual se imita sobre todo el primer verso del modelo. ${ }^{16} \mathrm{Y}$ ésta es una estrategia dominante en el modus imitandi de Boscán. En el soneto, junto al vocabulario petrarquesco clásico, resulta fundamental la presencia de elementos 'banales' pero emblemáticos — como, por ejemplo, los pronombres personales «voi» e «io» con sus derivados-, que colocan de inmediato los versos boscanianos en la órbita del Canzoniere. Además, el segundo cuarteto imita también el soneto proemial de las Rime de Bembo, que ya llevaban más de diez años publicadas cuando salieron las Obras de Boscán y que constituyeron otro texto de referencia para el escritor catalán en los años de su decisivo acercamiento a la poesía «a la manera italiana».

14. Para los textos del «Libro II», citamos siempre de Boscán-De la Vega (1995).

15. Para Otis Green tanto el soneto de Boscán como el de Petrarca constituirían una "palinodia anticipada». Cf. Green (1969: I, 163).

16. Cf. Erspamer (1987a: 111-112). 
Boscán:

Esto siempre juzgó mi entendimiento: que d'este mal tod'hombre se guardase, y así, porque'sta ley se conservase, holgué de ser a todos escarmiento.

(XXIX, vv. 5-8)
Bembo:

Ché potranno talor gli amanti accorti, queste rime leggendo, al van desio ritoglier l'alme col mio duro exempio.

Si Petrarca, como consecuencia de su desvarío amoroso, pronosticaba para sí mismo la vergüenza ante la gente y ante Dios mismo (Ma ben veggio or si come al popol tutto / favola fui gran tempo, onde sovente / di me medesmo meco mi vergogno / et del mio vaneggiar vergogna è l frutto), sus epígonos del XvI, quizá siguiendo en esto la general actitud preceptiva de la época, de la íntima consternación subrayan principalmente el valor de ejemplo y enseñanza para los demás: ése es el auspicio de Bembo (ritoglier l'alme col mio duro exempio), y también el de Boscán (holgué de ser a todos escarmiento). Por lo tanto, el soneto introductorio del «Libro II» intenta enderezar las composiciones sucesivas hacia una interpretación bien orientada desde un punto de vista moral: igual que ocurre en $R V F$, lo que se establece es una especie de contrato con los lectores para que sientan el estímulo de reconstruir, más allá de la multiplicidad temática y formal de los textos, la unidad de un testimonio y un itinerario autobiográfico, la 'historia de un alma'. Sin embargo, a pesar de la rigurosa imitación del soneto proemial, los 102 poemas (XXIX-CXXX) que componen el libro ${ }^{18}$ no siguen un único e ideal desarrollo: por el contrario, como es sabido, parecen dar lugar a una especie de doble cancionero dentro del mismo conjunto $^{19}$. Si es cierto que tampoco $R V F$ procede de modo sintagmático, la escisión que encontramos en las páginas de Boscán es completamente distinta. De hecho, la división del Canzoniere es funcional al arrepentimiento y a la conversión del protagonista-autor y, por ello, perfectamente homogénea respecto al significado último de la obra; en cambio, en el «Libro II» la propuesta poética sigue siendo la misma - el soneto proemial ya advierte del peligro que nace del sentimiento amoroso-, pero el modo de proceder, y sobre todo su

17. Para el texto bembiano, cfr. Bемвo (1966). Sobre la relación directa entre las 'tesis' y los versos de Bembo y el «Libro II» de Boscán, con ulteriores referencias bibliográficas, cf. directamente LeFÈvRE (2006: 15-27).

18. Hay que notar que, si se quitaran los dos sonetos 'extravagantes' (CXXVIII-CXXIX) dedicados a la muerte de su amigo Garcilaso, el cancionero de Boscán constaría de 100 poemas, lo que, incluso númericamente, remitiría a una costumbre estructural y editorial de la poesía italiana de la época: al respecto, sólo para citar un par de ejemplos casi contemporáneos a las Obras de Boscán, véanse los Cento sonetti de Alessandro Piccolomini (Roma, Vincenzo Valgrisi, 1549) y los de Anton Francesco Raineri (Milano, Giovanni Antonio Borgo, 1553).

19. Sobre la estructura peculiar del "Libro II", cf. PARduCCI (I952); DARST (1978); y especialmente ArMisén (1982: 379-411), que además ha subrayado en más de una ocasión las afinidades entre la poesía de Boscán y el itinerario minucioso de $R V F$. Últimamente, a este respecto, cf. también REA (2007). 
epílogo, resulta muy independiente de la trayectoria petrarquesca, así que el cancionero de Boscán resulta orientado y estructurado en torno a dos centros. Como veremos, en la experiencia principal del trastorno erótico y del «dolorido sentir», el poeta catalán, por un lado, cierra el «Libro II» de forma 'ortodoxa', con la palinodia celebrada por la canción CXXX, de evidente sabor petrarquesco, y por otro, acercándose la conclusión de la 'historia', también incluye una corona de sonetos (CXIV-CXXVII) dedicados a su esposa y al amor conyugal, sereno y feliz, que da vida a un núcleo autónomo y sintetiza el fin de sus penas precedentes. ${ }^{20}$ Así, para salvar al poeta de su atormentada vivencia erótica intervienen dos soluciones diferentes: una perfectamente petrarquista y, por ello, literaria y postiza, en la que el poeta rechaza la vanidad del sentimiento amoroso en nombre del encuentro con Dios; ${ }^{21}$ y otra antipetrarquista y, por así decir, 'burguesa', basada en la fuga de la frustración erótica en nombre del matrimonio, y de una variante positiva y socialmente aceptada del sentimiento, que además resulta más auténtica porque está ligada a la vicisitud real del poeta. ${ }^{21} \mathrm{Y}$ la concomitancia, en el mismo corpus, de estos dos caminos, si bien es inconcebible según la perspectiva del Canzoniere, en realidad no invalida en absoluto el proyecto de Boscán: los avatares del 'autor-personaje' se desarrollan de modo coherente desde el soneto proemial justamente hasta la escisión final, donde una de las vías que toma es supuestamente genuina, fundada en la experiencia concreta, mientras que la otra responde a las exigencias del sistema literario. En el libro de Boscán la vida parece anteponerse a la lírica, lo privado a lo universal, lo humano a lo divino: el rescate de una condición de pecado y

20. En su estudio sistemático sobre la lírica de Boscán, Amos Parducci, con una reconstrucción fundada tanto en el aspecto puramente poético como en el biográfico, ha dividido el libro entre poemas «dell'amore tormentoso» y poemas «dell'amore casto». Cf. PArducci (1952: 6-7). Como la boda entre el poeta y Dońa Anna Girón de Rebolledo puede fecharse en 1533, Parducci concluye, aunque de un modo demasiado automático, que «ai due periodi così diversi fra loro corrisponde pure la diversa intonazione della lirica» (ibid., p. 7). Según este planteamiento biográfico, sería posible entonces, para Parducci, identificar dos 'momentos' diferentes - fechables de modo neto y riguroso- en la poesía amorosa de Boscán: una primera fase, borrascosa, ligada a la pasión por la bella e inalcanzable nobildonna catalana Isabel (ibid., pp. 24-26); y una segunda fase, más tranquila y sobre todo satisfactoria, inspirada en la serenidad de la relación con su mujer.
21. Como ha indicado, entre otros, Guglielmo Gorni, los fieles seguidores de la manera de Petrarca al final de un cancionero prefieren poner generalmente una canción —elevación analógica en el plano de la expresión y de la dignidad poética respecto al soneto inicial- de claro marco espiritual y sagrado; es decir, una oración. Por ejemplo, la canción conclusiva de las Rime de Bembo está dirigida al Omnipotente (Signor, quella pietà, che ti constrinse), y también Della Casa, por mencionar a otro petrarquista 'devoto', se mueve en la misma dirección (Questa vita mortal chén una ón due). Cf. GoRNI (1989: 39). 21. Cabe decir que también en el petrarquismo italiano hay ejemplos de sillogi y cancioneros 'matrimoniales' que, aun manteniendo ciertas prerrogativas de la imitación de $R V F$, precisamente se desvían de la imitatio vitae más rigurosa y definen nuevas opciones literarias, sociales y éticas. Cf., al respecto, Gigliucci (2000: 652 y ss.; 672; 957; 961 y ss.) 
desvarío se produce a través de una circunstancia común, anodina -el casamiento entre un caballero y una joven nobildonna - y, sobre todo, para nada espiritual; parece que al poeta le agrada contar el sosiego y el placer que nacen de un amor estable y consumado. La supuesta conversión del poeta se realiza, de esta suerte, tanto en su dimensión 'oficial', elitista y literaria, con todas las implicaciones que conllevan la poesía y la axiología petrarquesca, como en su variante prosaica - el contrato matrimonial—, que es el auténtico consuelo del poeta en los últimos años de su vida y que, al mismo tiempo, resulta ser distinto al mensaje aristocrático y al anhelo espiritual de $R V F$.

La distancia de Petrarca es enorme, y dos son las causas principales que alejan a Boscán del sistema moral del Canzoniere. Ante todo, según la perspectiva petrarquesca, para salvarse del «errore» y de los lazos de Amor, hay que abandonar toda forma de pasión humana y dedicarse solamente al amor divino: en este sentido, no es posible ni aceptable la celebración de un amor igualmente terrenal, aunque puro y hasta santificado por el matrimonio. En segundo lugar - y ésta es una razón aún más sutil, filosófica- el sistema de valores propugnado por el poeta italiano, que en cierta medida responde a la visión medieval del amor y la fe, prevé una única posibilidad de salvación para el alma: así, el hecho mismo de que el libro de Boscán tenga dos epílogos, dos soluciones diferentes que redimen al poeta, resulta intolerable, ya que tal 'duplicidad' se podría tomar peligrosamente por ambigüedad o, incluso, hipocresía. La palinodia y el arrepentimiento del autor español, por mucho que se adhiera en parte a los usos del petrarquismo, no llega a alcanzar la sublimación espiritual y el rechazo del eros que, en cambio, Petrarca activa principalmente en la segunda parte de $R V F$ y que se vuelve la razón última y unívoca de su canto. En este sentido, el de Boscán es un cancionero imposible, ya que contraviene al sistema axiológico del Maestro: para el poeta italiano, solamente el amor divino puede salvar al individuo (poético y 'en carne y hueso') y éste tiene que librarse necesariamente de cualquier tipo de amor humano, independientemente de que este último sea de tipo profano, cortesano o incluso conyugal.

De acuerdo con las orientaciones del petrarquismo más ortodoxo, fijado en sus coordenadas estilísticas y éticas por Bembo, en las décadas centrales del Xvi la idea misma de 'cancionero' parecía contemplar la descripción de una parábola lírica y autobiográfica que llevara al sujeto a la liberación de las pasiones terrenas y a la redención definitiva. Y esta propuesta se hacía aún más radical según iba acompañada no sólo por el respaldo de la élite crítica y literaria italiana de la época — in primis los comentaristas del Canzoniere-, sino también por la vivencia de sus principales divulgadores: entre ellos, por ejemplo, el cardenal Bembo y monsignor Della Casa, quienes habían dejado la vida mundana por hacerse pastores de la Iglesia. Respecto a la vocación profana y ecléctica de la poesía de principios del XVI — nos referimos a la generación de Serafino Aquilano, Olimpo da Sassoferrato, Notturno Napolitano, etc.—, y antes de los cancioneros más complejos, abiertos y multiformes de la segunda 
mitad del siglo, de los ańos treinta en adelante lo que se proponía era una normalización y espiritualización de la lírica, que envolviera toda la persona humana y que, como hemos visto, también encajaba con los auspicios de la ideología imperial y curial. Sin embargo, ni el mundo poético italiano ni el español asumió el modelo petrarquista hasta sus extremas consecuencias, ya que muy pocos autores se conformaron con la imitatio vitae hasta en sus implicaciones religiosas e ideológicas: en este sentido, a excepción de pocos casos, hay que reconocer que todo petrarquismo es 'heterodoxo', o por lo menos incapaz de reproducir de forma satisfactoria y creíble la estructura moral y teleológicamente orientada de $R V F$. A lo largo del xvi el petrarquismo se vuelve una variante elitista de la literatura y la conducta, que en el mundo hispanoitaliano coincide con la moda cortesana y la «forma del vivere» renacentista, símbolos de una nueva época cultural, y precisamente en este contexto y en este clima intelectual se coloca la producción poética de Boscán, Garcilaso y toda la primera generación del petrarquismo ibérico ${ }^{22}$, que recupera motivos, metros e, incluso, cierta atmósfera espiritual presente en el Canzoniere, distanciándose al mismo tiempo de su integralismo ético.

En esta distancia más o menos programática, en esta imposibilidad de reproducir tout court un cancionero al modo petrarquesco, se halla la peculiar 'conversión' de Boscán, la solución temática — y moral— de su proyecto lírico, que es interesante reconstruir justamente en su reverencia y 'rebelión' ante el modelo, en sus variaciones que igualmente intentan diseñar el propio itinerario poético y existencial.

El soneto inicial del «Libro II» de Boscán, igual que en Petrarca, está acompañado por unos poemas que completan y modulan su función de apertura: los tres sonetos inmediatamente sucesivos (XXX-XXXI-XXXII) ayudan, en efecto, a encaminar la aventura humana y poética del autor. ${ }^{23}$ Ante todo, recuperando la instancia más significativa del proemio, el XXXI y el XXXII subrayan el valor de advertencia, de "escarmiento", que las vicisitudes del poeta deberían tener para los demás hombres. En el primero de los dos, Boscán invita a desconfiar de los falsos lazos de Amor, para que los lectores se asusten («s'espanten») y no caigan en su mismo error:

las llagas que, d'Amor, son invisibles, quiero como visibles se presenten, porque aquellos que umanamente sienten

22. Para la división del petrarquismo español por 'generaciones', recuérdese el estudio de Fucilla (1960).

23. Cabe decir que, según Anne J. Cruz, como veremos más adelante, también la canción XLVII del poeta catalán, la primera del libro, puede asimilarse al proemio de $R V F$, ya que evoca de modo evidente los motivos del arrepentimiento y de la confesión, que, sin embargo, afloran menos en los sonetos recién mencionados. Cf. Cruz (1989: 175). Al respecto, véanse también Cruz (1988 y 1990). 
s'espanten d'acidentes tan terribles.

Los casos de justicia más horribles

en público han de ser; porque'scarmienten

con ver su fealdad, y s'amedrienten

hasta los coraçones invencibles

(XXXI, vv. 1-8)

En una óptica didáctica, sus desventuras, equiparadas a crímenes, han de ser manifiestas («Los casos de justicia más horribles/ en público han de ser»), para que tanta ignominia desencadene el justo temor. De hecho, en este último detalle insisten también los tercetos del mismo soneto:

por el ancho camino por do fueren

todos verán mi triste monumento

y verán de mi muerte'l gran letrero.

Temblando quedarán en un momento

cuantos allí miraren y leyeren

un modo de morir tan lastimero.

(XXXI, vv. 9-14)

La admonición que el poeta ha repetido varias veces no deja excusas al lector: quienquiera que conozca el "triste monumento" que representa la experiencia del autor, como él mismo vuelve a afirmar en el soneto XXXII, debe tenerlo muy en cuenta o, de lo contrario, aceptar un destino amargo:

los que tras mí vernán, si se perdieren, no sé cómo podrán ser disculpados.

Morirán a sabiendas, si murieren.

Dinos serán de ser al campo echados, por mano de las gentes que los vieren tan adrede morir desesperados.

(XXXII, vv. 9-14, cursiva mía)

En realidad, ya en los tercetos del soneto XXX Boscán, en clara analogía con el modelo petrarquesco, alude a la vergüenza que le provoca narrar su propia «istoria» y anuncia sintéticamente el tema de su canto:

yo traigo aqui la istoria de mis males

donde hazañas d'amor han concurrido, tan fuertes, que no sé cómo contallas.

Yo solo en tantas guerras fui herido, y son de mis heridas las señales tan feas, que é verguença de mostrallas.

(XXX, vv. 9-14, cursiva mía)

Son versos que desde el punto de vista temático se completan precisamente en los dos sonetos sucesivos: 
mas converná mostrar mis desventuras;

que así serán pagadas mis locuras

con la triste verguença que sintiere

(XXXI, vv. 2-4, cursiva mía);

y:

delante van las penas quén mi siento

dando nuevas de mi desasosiego

(XXXII, vv. 5-6, cursiva mía).

La parte proemial del cancionero de Boscán respeta los cánones enunciativos y la mirada retrospectiva fijada por $R V F$, situando así, desde el principio, sus poemas «a la manera italiana» en la órbita petrarquesca. Y más adelante, precisamente en su intento de imitar lo más posible al Canzoniere, el autor traza un camino poético a través de sonetos y canciones que intenta diseñar propiamente una parábola existencial mezclando la tópica con la autobiografía. La misma solución del conflicto y de los tormentos amorosos con el matrimonio, cuyo reflejo es el microcancionero al que hemos aludido varias veces, de hecho, confirma de modo elocuente la constancia de una vertiente autorreflexiva y personal. Y los indicios que denuncian una trayectoria narrativa en los poemas permiten también determinar con claridad esos factores de cohesión, en la esfera textual y macrotextual, que forman la arquitectura temática y moralizante de todo el conjunto y hacen que la imitación del modelo no se apoye sólo en componentes exteriores, formales, sino también en el intento, por parte del poeta, de integrar de alguna manera la imitatio styli con la imitatio vitae. ${ }^{24}$ Sin embargo, las referencias a algunos célebres poemas de $R V F$, si bien condicen con la estructura progresiva del libro y, por ello, con la funcionalidad semántica del proyecto de autor, no bastan de por sí para reconstruir con igual realismo una auténtica, aunque ficticia, vivencia humana: la mayoría de las veces el universo de imágenes y episodios creado por Boscán se muestra alusivo e indistinto, faltan referencias a lo concreto y a la realidad y, por lo tanto, tampoco se siente viva la cruda opresión del sufrimiento. En muchos casos, las situaciones son estereotipadas y Petrarca parece convertirse más en paradigma ineludible que en 'compañero de viaje'. ${ }^{25} \mathrm{~A}$ pesar de todo, algunos

24. Anne J. Cruz considera que tanto Bembo como Boscán «interpretan de manera literal la imitatio vitae: como una narración ficticia de la experiencia vivencial del poeta que lleva a una resolución palinódica». Cf. Cruz (1989: 169). En realidad, según hemos dicho y veremos en estas páginas, en el caso de Boscán la imitatio vitae permanece más que nada a un nivel formal, tópico, y no tiene nada que ver con su dimensión espiritual.

25. Con referencia a estas últimas consideraciones, parte de la crítica ibérica ha sostenido con razón la ausencia de una profundidad real en el cancionero boscaniano. Valga aquí la opinión de Antonio Prieto, según el cual lo que le falta al clima poético general de España es precisamente la adopción rigurosa del modelo petrarquesco como "historia de un proceso vital, más o me- 
ejemplos ponen de relieve la atención que, indudablemente, dentro del «Libro II» Boscán presta a la disposición de las composiciones, y al mismo tiempo demuestran el deseo de esbozar, aun con todos los límites del caso, la 'historia de un alma', en cuyo ámbito la misma variedad métrica constituye un análogon formal de las distintas etapas de la experiencia humana y poética.

Por ejemplo, el soneto XXXIII, situado inmediatamente después de las composiciones con función de prólogo, anuncia de forma explícita la voluntad de Boscán de reconstruir retrospectivamente su propia historia. En los dos cuartetos se describe, pues, el principio de las aventuras amorosas del poeta, quien parece predestinado, o mejor, condenado desde la infancia a padecer los ataques de Amor.
Aún bien no fui salido de la cuna, ni de l'ama la leche uve dexado, cuando el amor me tuvo condenado a ser de los que siguen su fortuna.
Diome luego miserias d'una en una por hazerme costumbre en su cuidado; después en mí d'un golpe ha descargado cuanto mal hay debaxo de la luna. (XXXIII, vv. 1-8)

Los versos contienen una especie de breve flashback existencial, una narración in nuce, pero también aquí el análisis retrospectivo procede de manera meramente retórica: si Petrarca vuelve atrás en la memoria hasta el momento del fatídico encuentro con Laura, brindando al lector detalles cronológicos precisos y al mismo tiempo simbólicos, vinculados con su experiencia espiritual (Era il giorno ch'al sol si scoloraro; Benedetto sia'l giorno, él mese et l'anno; etc.), Boscán prefiere mantenerse más anecdótico y 'fija' su condena a partir de la cuna, aumentando después de modo hiperbólico la ejemplaridad de su propio caso. Así,

nos autobiográfico, medularmente centrado en una relación amorosa que exige la presencia de una amada a la que dirigirse y que, con su muerte, divide la historia en in vita e in morte de la amada». Cf. Prieto (1984: I, 33). Sin embargo, hay que subrayar que, con una óptica demasiado 'integralista', se corre el riesgo de juzgar implícitamente desviado o parcial todo intento finalizado a imitar el modelo de RVF: Prieto ha insistido, por ejemplo, en que el petrarquismo del autor catalán «como el de tantos poetas cortesanos, no era, claro está, un entendimiento del Canzoniere ni un intento de crear un cancionero propio». Cf. Prieto (1984: I, 64). Por lo tanto, el paso declarado al petrarquismo, según Prieto, no comporta, en Boscán, tampoco una asunción del significado profundo de la obra, una identificación más o menos programática entre su vivencia poética y humana y la perspectiva del autor italiano. Más bien, la única novedad relevante residiría solamente en la manera poética, y en todo lo que ésta conlleva: «Hay un importante cambio del Boscán cancioneril al Boscán italianizante, mas este cambio, con su repercusión, es solamente formal, con cuanto la forma exige [...] el poeta cancioneril que andaba fingiendo amor, amor cortesano, en coplas castellanas, es el mismo poeta que ahora finge en endecasílabos, sin que exista una coherencia interna, un proceso que pudiera ordenarse secuencialmente, con la recurrencia y progreso de determinados sintagmas o apelaciones míticas» (Ibid.). 
el poeta español pierde al mismo tiempo aquel contacto con la dimensión real que hacía más creíble y, a la vez, más profundo el itinerario de 'conversión' del poeta italiano. ${ }^{26}$

En esta perspectiva, también la canción XLVII, aun tratando de manera larga y tendida sus tormentos, no deja de comunicar cierta sensación de artificiosidad. La parte 'narrativa' comienza en el v. 91 y alterna referencias a eventos paradigmáticos y genéricos con situaciones que, por el contrario, aunque se adhieren más a la realidad, quedan bastante lejos de la fuerza realista del Canzoniere. Ante todo, resulta abstracta la descripción de la herida inicial de amor:

cuando el amor cobré

no sé cómo no ví el mal que tenía.

Tan cautelosamente me hería

que apenas lo sentía.

(XLVII, vv. 91-94)

Y también la parte siguiente, dedicada a la observación de los síntomas del enamoramiento, carece de las alusiones a la realidad puntual:

cosas sin fin, y nuevas,

hazía no sé cómo, sin pensallas.

La novedad ya de'llas me'spantava

y no osava mirallas.

[...]

Crecía el miedo de lo por venir, y ocorríanme mil cosas contadas, que'stavan olvidadas,

por espantarme y hazerme morir.

(XLVII, vv. 106-116)

La conciencia de la naturaleza inexorable e incurable del sentimiento amoroso hacia la amada asume, a su vez, un tono enfático, según un modelo típico de la lírica del xv, que se refleja en la sentencia epigramática con la que Boscán liquida la cuestión y acaba por banalizar el tono de toda la canción:

cuando pude curarme, no lo ví;

agora que no puedo, lo entendí.

(XLVII, vv. 149-150) ${ }^{27}$

26. En esta clave hay que leer también la exageración de los vv. 7-8, según los cuales, y a causa de su inquietud amorosa ("cuidado»), sobre el destino de Boscán habría caído todo el mal de este mundo («en mí d'un golpe ha descargado/ cuanto mal hay debaxo de la luna»).
27. En particular, sobre el carácter arrollador del sentimiento amoroso, véanse también XCIX y, sobre todo, XLI, cuyo primer verso, además, es un evidente calco petrarquesco ( Dexadme en paz, ¡o duros pensamientos! $»=$ «Datemi pace, $\mathrm{o}$ duri miei pensieri», RVF, CCLXXIV). 
La segunda parte de la misma canción, que se genera como consecuencia de la comprensión, por parte del poeta, de su destino amargo, queda más vinculada a una dimensión vivencial; sin embargo, ésta tampoco resulta muy definida —el nombre de la amada no se pronuncia nunca y, aparte de algunos deícticos (luego, agora, antes, etc.), falta cualquier tipo de alusión espacio-temporal-, y hasta en los versos donde se analizan el deseo y el temor a declararse y se describe la confesión agitada de los sentimientos (vv. 241-300), Boscán parece seguir siendo, sobre todo, prisionero del intelectualismo cancioneril, ya que cede a continuas interrogaciones retóricas y a razonamientos afectados. Quizá el aspecto más interesante - y abiertamente petrarquesco- de la canción es la articulación del discurso en dos niveles temporales: por un lado, la narración en pasado de su propia historia y, por otro, la reflexión sobre sus vicisitudes y su valor de ejemplaridad en el tiempo presente, que ocupa más o menos enteramente los últimos ciento cincuenta versos de la composición (sobre todo a partir del v. 319, «Esto se dize amar»...).

No obstante, en general, el cancionero de Boscán, aunque proponga de vez en cuando una estructura diacrónica, supuestamente in fieri, se muestra carente de una efectiva coherencia 'narrativa' y de una auténtica evolución espiritual: por una parte, como decíamos, le falta todo el aparato de referencias concretas a los días, los lugares, los encuentros, etc., que dan vida auténtica al Canzoniere; por otra, es prácticamente imposible detectar en sus versos las huellas de una conversión cristiana. En este sentido, la misma canción CXXX, de evidente sabor petrarquesco, no es más que un tributo literario y un requisito que cumplir respecto a un género y un modelo. A raíz del doble epílogo de su libro, podríamos decir que el autor español intenta 'servir a Dios y al mundo', y esto es lo que hace de su proyecto lírico un cancionero imposible, lo que inexorablemente lo aleja de Petrarca, de su compromiso literario y ético. Sin embargo, esta 'imposibilidad' no es una peculiaridad del propio Boscán, sino una característica del petrarquismo en general, que tanto en Italia como en España, a pesar de la exegesis y la 'catequesis' bembiana, cada vez más a menudo toma caminos distintos al del Maestro. Así, el poeta barcelonés, con su propuesta lírica y su peculiar hermenéutica petrarquesca, intenta distanciarse, tanto de la tradición castellana rumbo al 'nuevo mundo' renacentista e italianizante, como de cierto exceso teórico propio de la poesía y la crítica italianas del primer cuarto del XvI, ideando y esbozando una ruta personal hacia el petrarquismo.

A pesar de todo, a lo largo de su cancionero, Boscán también incluye una serie de poemas de arrepentimiento al estilo de $R V F$, sin embargo, como hemos dicho, estas composiciones, independientemente de la postiza oración final, aluden a una conversión 'terrenal' y prosaica: la erótica doméstica de la unión conyugal. Si Petrarca, temiendo por su alma, imploraba a la Virgen misericordia y regeneración, Boscán invoca y da las gracias a Dios no sólo por haberle alejado de su insana pasión amorosa - como unívocamente requiere la ortodoxia petrarquesca-, sino también por haberle permitido conocer un amor sano y casto en la paz matrimonial. 
Es lo que se puede vislumbrar ya al principio de su cancionero, en el soneto XL:

Vime al través en fuertes penas dado, casi sin vida, y lo demás perdido;

y entonces fui de seso tan caído que'n tanto mal me vístar descuidado. He'ntendido después tan mal estado cuando las gentes dél m’han advertido; y así agora, aunque'stoy arrepentido, no me contento, pues tanto he tardado. No tardé en entender luego el engaño, pero, de miserable, no quería acabar de creer tan fuerte daño.

Venció en fin la verdad a mi porfía y quedó confirmado el desengaño, tomando nueva vuelta el alma mía.

El «engaño» amoroso, fuente de pena y perdición, queda desvelado, sin embargo, no es un ejercicio personal de autoanálisis lo que le hace despertar del 'hechizo' («las gentes dél m’han advertido»). La reprensión, pues, llega tarde (vv. 7-8), tal vez porque a la conciencia de Boscán le falta precisamente otro paradigma ético más allá del amor humano y terreno, es decir, el anhelo espiritual. También el último terceto, que establece por fin la victoria de la verdad respecto a la ilusión, admite una renovación del alma («tomando nueva buelta el alma mía»), pero el procedimiento se funda en una retractación basada en el desengaño y el sentido común, y no en explícitas alusiones a una conversión cristiana, a una 'Verdad' con mayúscula.

Sin detenernos ahora en los sucesivos poemas de arrepentimiento que aparecen en la parte central del "Libro II» (XLI, LXVIII, etc.), parece que a partir del soneto $\mathrm{C}$ se percibe en los versos de Boscán una atmósfera de cambio y (laica) renovación. Este soneto es complejo y, como ha observado Caravaggi, está dotado de una «bivalenza semantica», ${ }^{28}$ ya que posee un significado literal y otro alegórico/simbólico.

En alta mar ronpidostá el navío con tempestad y temeroso viento, pero la luz que yảmanecer siento, y aun el cielo, me hazen que confío.

La'strella con la cual mi noche guío, a bueltas de mi triste lasamiento, alço los ojos por miralla atento, y dize que, si alargo, el puerto es mío. mia colma d'oblio). 
Da luego un viento que nos da por popa;

a maner de nubes vemos tierra;

y á rato ya que dizen que la vimos.

Ya començamos a enxugar la ropa,

y a encarecer del mar la brava guerra,

y a recontar los votos que hezimos.

$\mathrm{Al}$ evento real de la supervivencia al naufragio, según el topos clásico, se añade el naufragio simbólico del alma en tempestad que al final encuentra paz. Se trata, pues, de una salvación física y moral, sin embargo, la dimensión ética no implica de por sí una conversión espiritual y, en particular, religiosa. Además, las comparaciones y similitudes marítimas son bastante frecuentes en Boscán, especialmente en la sección inspirada por el amor a su esposa: ${ }^{29}$ el puerto seguro, entonces, la paz que el poeta alcanza, no es aquella que sólo Dios concede a sus hijos, como quería Petrarca, sino del hogar doméstico,igualmente mente digna y aceptada.

Además, el poeta confiesa a menudo la dificultad de un cambio auténtico y duradero: es lo que destaca en las canciones CIII y CIV, en las que predomina una dimensión autorreflexiva. En la segunda, en especial, el balance de la vivencia erótica del autor se describe según el criterio de una experiencia ya terminada (abundan los tiempos en pasado absoluto, por ejemplo, y sin salirnos de la esfera formal, en la parte más significativa de la composición):

en otro tiempo, pues, pasé mi vida

de tal suerte que,'n fin, yo la pasava

concertándome en mí con mis tormientos.

(CIV, vv. 46-48, cursiva mía)

El soneto CXIII completa la serie de poemas que someten a examen la aventura 'venérea' de Boscán y que declaran, más o menos abiertamente, la renuncia de éste a las pasiones del pasado. Su posición y su contenido son ambos estratégicos: desde el punto de vista estructural, el poema introduce la corona de sonetos del amor casto; desde el punto de vista semántico, enlaza también con el primero de éstos, que celebra sin rémora el renovado horizonte conquistado por Boscán y por su canto. En efecto, precisamente en el soneto CXIV la renuncia a los dolores y a las antiguas seducciones de Eros se cumple por medio de una convencida elección del amor conyugal, un amor pacificado que colma de alegría y quietud al poeta. ${ }^{30}$ Así, Boscán, abriendo su singular microcancionero matrimonial, proclama

29. Vid. también RVFCVII; CXVI; e CXXIII. 30. Como afirma acertadamente Parducci, los versos dedicados al amor por la esposa analizan, de manera sustancialmente unívoca y a veces hasta monocorde, el tema del «contrasto costante fra la felicità dell'amore presente e la infelicità dell'amore ben morto». Cf. PARDUCCI (1952: 27). Por otro lado, las cualidades esenciales de este 'nuevo' amor, más allá de la monotonía tonal y temática, están ligadas a la esfera del «sosiego», de la calma, tras tantos años de vanas aflicciones. 
inmediatamente su nueva conquista tanto en el plano moral como poético, y los célebres primeros versos del soneto sintetizan precisamente esta doble perspectiva:

otro tiempo lloré y agora canto, canto d'amor mis bienes sosegados (CXIV, vv.1-2)

Los sollozos dejan aquí espacio a la tranquillitas animi y a la serenidad amorosa. Los versos están inspirados por un universo de pureza y profunda satisfacción:

agora empieça Amor un nuevo canto, llevando así sus puntos concertados, que todos, de'star ya muy acordados, van a dar en un son sabroso y santo.

(CXIV, vv. 5-8)

La razón vence a la pasión y el nuevo sentimiento no sólo es fuente de placer y felicidad, sino que también resulta absolutamente lícito (miscere utile dulci...) en la perspectiva moral y civil:

Razón juntó l'onesto y deleitable, y de'stos dos nació lo provechoso, mostrando bien de do engendrado fue.

(CXIV, vv. 9-11, cursiva mía)

En efecto, en los poemas sucesivos, con frecuencia el registro lírico encuentra el campo semántico de la dulzura, ${ }^{31}$ como demuestra el incipit del soneto CXVI:

amor m’embía un dulce sentimiento;

y, sobre todo, el soneto CXIX, que a través de una serie de anáforas corrobora el goce profundo y el sosiego que el nuevo y «dulce» sentimiento confiere al autor.

Dulce reposo de mi entendimiento;

dulce plazer fundado sobre bueno;

dulce saber que de saber soy lleno, pues tengo de mi bien conocimiento.

Dulce gozar d'un dulce sentimiento, viendo mi cielo'star claro y sereno, y dulce rebolver sobre mi seno, con firme concluir que'stoy contento. Dulce gusta d'un no sé qué sin nombre, que Amor dentro en mi alma poner quiso, cuando mi mal sanó con gran renombre.

31. Sobre el tema de la dulzura en la parte conclusiva del cancionero de Boscán, véase también ARMisÉn (1982: 402). 
Dulce pensar que'stoy en paraíso;

sino que,'n fin, m'acuerdo que soy hombre,

y en las cosas del mundo tomo aviso.

Y la correspondencia entre marido y mujere es precisamente lo que más contribuye a ese estado de gracia presente ya en la vida y en la poesía de Boscán:

antes terné qué cante blandamente,

pues amo blandamente y soy amado

(vv. 1-2);

así yo de ver quien me ama y a quien amo,

en mi cantar terné gozo contino.

(vv. 13-14)

Si en la primera parte del «Libro II» predomina el campo semántico de la inquietud y del sufrimiento, en esta singular sección recurren, para la definición de Amor, adjetivos que evocan la esfera de la tranquilidad, la dulzura, el goce, así como la licitud y la moralidad. En el primer terceto del soneto CXIV, por ejemplo, es curioso notar que el poeta catalán evoca y revisa, a la luz de lo que estamos diciendo, uno de los conceptos fundamentales de la reflexión renacentista, es decir, la doctrina de utile dulci: el contacto de los términos «honesto» $\mathrm{y}$ «deleitable» confirma, en última instancia, la modernidad de la propuesta de Boscán, en la que el amor, en vez de ser totalmente rechazado, como predicaban Petrarca y sus epígonos más devotos, queda recuperado y ennoblecido con vistas a una definición completa de la persona, según quería la doctrina neoplatónica y cortesana. En los catorce poemas que forman el elogio del amor conyugal, pues, de forma anti-petrarquesca (y anti-metafísica), el poeta español consigue recuperar el sentimiento amoroso en una dimensión no sólo serena y sosegada, sino también moralmente digna para la vida del hombre.

Por todo ello, la tesis de Boscán se basa en la certeza de que el amor terrenal no aleja al ser humano de su Creador; al revés, el mismo Dios es mensajero y artífice de la riqueza duradera que mana de este sentimiento. Es lo que podemos notar, por ejemplo, en el soneto CXVIII:

un nuevo Amor un nuevo bien m'ha dado, illustrándome'l alma y el sentido, por manera que a Dios ya yo no pido sino que me conserve en este'stado. (CXVIII, vv. 1-4);

y más aún en el CXXVII:

El casto Amor, que Dios del cielo embía, le dixo en ver la pena que pasava: «Suelta tus pies, tus manos te destrava, toma tu lecho a cuestas y haz tu vía!» 
Bolví luego a mirarme y vime sano,

[...]

¿O poder eternal y soberano!

¿Quién sanará con propia diligencia

si la salud no da tu larga mano?

(CXXVII, vv. 5-14) $)^{32}$

$\mathrm{Al}$ acabar su corona matrimonial, Boscán introduce también un 'segundo' epílogo, que concluye el «Libro II ${ }^{33}$ con un homenaje a la tradición petrarquista: la canción CXXX, dirigida al Padre celeste. La nueva poesía «a la manera italiana» siente, pues, la necesidad de volver a su inspirador, a Petrarca, su modelo y numen: a pesar de la celebración del eros conyugal, el autor no se exime de cerrar su florilegio poético con un éxplicit petrarquesco, legítimo y 'ortodoxo' y, sobre todo, bien identificable. Estos versos, como en Bembo y Della Casa, responden a una exigencia estructural precisa, a una circularidad ${ }^{34}$ de la que ningún petrarquista puede prescindir a la hora de componer su cancionero. Sin embargo, como ya hemos resaltado, esta oración final no puede no resultar una retractación artificiosa y exclusivamente literaria, ya que para Boscán la única 'conversión' posible (y experimentada) respecto a la loca pasión del pasado se reduce a la conquista de otro tipo de amor, más puro y delicado pero igualmente terrenal.

A pesar de ello, si analizamos la canción CXXX, Boscán sigue de forma atenta el modelo petrarquesco. Hace referencia al sentido del pecado y de la culpa y, por ejemplo, recurre varias veces al término «error» en la acepción predilecta por el autor del Canzoniere:

duraron largo tiempo estos errores

(CXXX, v. 46);

pues Tú, Señor, olvidas

tu perjuicio de mi culpa clara

(CXXX, vv. 87-88);

mis errores veré, mas ya los veo

y entiendo bien el vano fundamento

sobre'l cual levantava mi cuidado

(CXXX, vv. 106-108).

Asimismo, el poeta invoca al Omnipotente para que lo libere de su insana pasión, escudrinándola y deplorándola precisamente para exaltar la grandeza del perdón divino:

32. Nótese el eco evangélico que aparece abiertamente en el imperativo divino de los versos 7-8. 33. Los sonetos CXXVIII y CXXIX, compuestos en ocasión de la muerte de su amigo Garci- laso, no hay que considerarlos en esta trayectoria, pues están ligados a dicha circunstancia luctuosa $y$, por tanto, separados del andamiento general. 34. Cf. Armisén (1982: 405). 
Tú, Dios, con tu sentencia me'nterraste'n dolores tan continuos, porque después me diese tu clemencia que otro Lázaro fuese'n tu presencia. (CXXX, vv. 72-75)

Y para ilustrar la auténtica regeneración de su persona, en la conclusión de su parábola, Boscán se compara hasta al Lázaro evangélico, confirmando, una vez más, el valor de exemplum que debería asumir su vivencia para los lectores:

Lo que puedo mostrar a todo el mundo

es que me perdí yo en este camino, y que anduve por él siempre perdido.

[...] más vino, primero que del todo anocheciese, quien con la gracia del poder divino el error me quitó y el desatino.

(CXXX, vv. 136-150)

Gracias a esta canción de arrepentimiento - y los ejemplos se podrían multiplicar- Boscán reproduce una estructura cerrada, cíclica, inspirada en $R V F$, cuya esencia se anuncia ya a partir del soneto-prólogo. Así, la composición final corrobora el motivo con el que el autor había abierto su cancionero, es decir, la advertencia y enseñanza al lector a través de la dramática historia de su alma, desde la depravación hasta la conversión y salvación por medio de la gracia divina. De este modo, Boscán intenta situar sus poemas a la italiana en el cauce del petrarquismo oficial, bembiano, que, como hemos dicho varias veces, se plantea tanto la imitatio styli como la imitatio vitae, la capacidad de 'narrar' en poesía una experiencia auténtica y autobiográfica similar a la del Maestro, ejemplar y exhaustiva de la inquietud humana. Sin embargo, según lo que hemos indicado hasta aquí, este intento aparece torpe o, por lo menos, artificial y hasta ambiguo con respecto al canto feliz y sosegado de sus rimas matrimoniales; es la prueba de la imposibilidad, para el poeta español, de recrear un cancionero ética y estéticamente compatible con la propuesta más radical de $R V F$.

El «Libro II» termina, pues, como había comenzado, en nombre de Petrarca, padre y modelo absoluto; sin embargo, en el caso de Boscán, la paternidad se reconoce sólo en la faceta literaria, funcional, digamos 'promocional'. El homenaje a la imitatio vitae, más que nada, es como una garantía de dignidad y éxito poético, y no una mera afinidad de carácter axiológico, ya que la visión del escritor español en el fondo difiere de la petrarquesca: para Boscán, el sentimiento amoroso no es fuente exclusiva de sufrimiento y perdición, y solamente hay que dirigirlo y administrarlo mejor; por el contrario, para el autor del Canzoniere, cualquier forma de amor, al estar dirigida a un objeto terrenal y, por ello, efímero, distrae al hombre de su itinerario hacia Dios y sólo puede comprometer su 
salud espiritual. Además, cabe decir que sucesivamente, por lo general, el petrarquismo hispánico no sigue ni el riguroso camino cristiano diseñado por $R V F \mathrm{ni}$ la trayectoria 'burguesa' y apaciguadora que el poeta catalán delinea en su libro: de hecho, los poetas italianizantes, empezando por el mismo Garcilaso, parecen no preocuparse demasiado por los problemas inherentes a la imitatio vitae en su versión más fiel, ni se refugian en absoluto en soluciones y fórmulas 'edificantes' al modo de Boscán. La primera generación petrarquista, en efecto, deja de lado el compromiso espiritual y teleológico del Maestro, mientras se aprovecha sobre todo de su repertorio léxico y métrico, estilístico y temático, dando vida a una nueva poesía, que no es sólo lírica, conjugando precisamente los elementos de clara ascendencia petrarquesca con los nuevos motivos y las nuevas formas del Renacimiento literario europeo. Y en esta oscilación constante y duradera entre observancia e independencia respecto al modelo, el cancionero 'imposible' de Boscán se hace esencial tanto para introducir y promocionar en España la nueva poesía, como para mostrar todos los límites y, al mismo tiempo, los infinitos recursos — lingüísticos, estilísticos, rítmicos y hermenéuticos- de la imitación del Canzoniere. 


\section{Bibliografía}

ArmisÉn Abós, Antonio, Estudios sobre la lengua poética de Boscán: la edición de 1543, Zaragoza, Universidad de Zaragoza, 1982.

Bembo, Pietro, Poesie e prose, ed. Carlo Dionisotti, Torino, UTET, 1966.

Boscán Almogaver, Juan-Garcilaso de la Vega, Obras completas, ed. Carlos Clavería, Madrid, Turner, 1995.

Burguillo López, Francisco Javier, "Notas para una revisión del concepto "Cancionero petrarquista»", La fractura historiográfica: las investigaciones de Edad Media y Renacimiento desde el tercer milenio, director Javier San José Lera, Salamanca, Seminario de Estudios Medievales y Renacentistas (SEMYR), Sociedad de Estudios Medievales y Renacentistas CERES de la Universidad de Kiel, 2008, 491-505.

Burke, Peter, The fortunes of the "Courtier», Cambridge, Polity Press, 1995.

Cabello Porras, Gregorio, «Sobre la configuración del cancionero petrarquista en el siglo de oro", Ensayos sobre tradición clásica y petrarquismo en el Siglo de Oro, Almería, Universidad de Almería, 1995, 13-37.

Cappello, Giovanni, La dimensione macrotestuale: Dante, Boccaccio, Petrarca, Ravenna, Longo, 1998.

Caravaggi, Giovanni, «Note», Juan Boscán, Liriche scelte, editor Giovanni Caravaggi, Torino, Einaudi, 1971.

Corti, Maria, «Testi o macrotesto? I racconti di Marcovaldo di I. Calvino», in Strumenti critici, 9 (1965), 182-197.

Cruz, Anne J., Imitación y transformación: el petrarquismo en la poesía de Boscán y Garcilaso de la Vega, Amsterdam-Philadelphia, John Benjamins Publishing Company, 1988.

—, «La imitación del modelo óptimo: Petrarca, Bembo, Boscán y la imitatio vitae», Revista Canadiense de Estudios Hispánicos, 13 (1989), 169-182.

—, «Spanish Petrarchism and the Poetics of Appropriation: Boscán and Garcilaso de la Vega", Renaissance Readings, Urbana-Chicago, University of Illinois Press, 1990, 80-95.

Darst, David, Juan Boscán, Boston, Hall, 1978.

ERSPAMER, Francesco, «Il canzoniere rinascimentale come testo o come macrotesto: il sonetto proemiale», Schifanoia, 4 (1987), 109-114.

—, "Centoni e petrarchismo nel Cinquecento", Scritture di scritture. Testi, generi, modelli nel Rinascimento, eds. Giancarlo Mazzacurati y Michael Plaisance, Roma, Bulzoni, 1987.

Fucilla, Joseph G., Estudios sobre el petrarquismo en España, Madrid, CSIC, 1960.

Gargano, Antonio, Con accordato canto: studi sulla poesia tra Italia e Spagna nei secoli XV-XVII, Napoli, Liguori, 2005.

Genot, Gérard, «Strutture narrative della poesia lirica», Paragone, 18 (1967), $35-52$. 
Gigliucci, Roberto, La lirica rinascimentale, Roma, Istituto Poligrafico e Zecca dello Stato, 2000.

Gorni, Guglielmo, «Il libro di poesia cinquecentesco: principio e fine», Il libro di poesia dal copista al tipografo. Atti del Convegno di Ferrara (1987), editores Amedeo Quondam y Marco Santagata, Ferrara, Edizioni Panini-Istituto di Studi Rinascimentali, 1989, 35-41.

Green, Otis H., España y la tradicción occidental. El espiritu castellano en la literatura española desde El Cid hasta Calderón), Madrid, Gredos, 1969.

Guidi, José, «Baldassar Castiglione et le pouvoir politique: du gentilhomme de cour au nonce pontifical", Les écrivains et le pouvoir en Italie à l'époque de la Renaissance, Paris, Université de la Sorbonne Nouvelle, 1973, 243-278.

—, «L'Espagne dans la vie et dans l'oeuvre de B. Castiglione: de l'équilibre franco-hispanique au choix impérial ", Présence et influence de l'Espagne dans la culture italienne de la Renaissance, Paris, Université de la Sorbonne, 1978, 113-202.

Lefèvre, Matteo, Una poesia per l'Impero. Lingua, editoria e tipologie del petrarchismo tra Italia e Spagna nell'epoca di Carlo V, Manziana (RM), Vecchiarelli Editore, 2006.

-, Il potere della parola. Il castigliano nel '500 tra Italia e Spagna (Grammatica, Ideologia, Traduzione), Manziana (RM), Vecchiarelli, 2012.

Longhi, Silvia, «Il tutto e le parti nel sistema di un canzoniere», Strumenti critici, 39 (1979), 265-300.

Lorenzo, Javier, "Nuevos casos, nuevas artes». Intertextualidad, autorepresentación e ideología en la obra de Juan Boscán, New York, Peter Lang, 2007.

Middlebrook, Leah, Imperial Lyric. New Poetry and New Subjects in Early Modern Spain, Pennsylvania State University Press, 2009.

Morros Mestres, Bienvenido, Las polémicas literarias en la España del siglo XVI: a próposito de Fernando de Herrera y Garcilaso de la Vega, Barcelona, Quaderns Crema, 1998.

—, «El Canzoniere de Boscán (Libro II, Barcelona, 1543)», Revista de filología española, 85 (2005), 245-270

Ossola, Carlo-Prosperi, Adriano, La Corte e il "Cortegiano", I: La scena del testo, a cura di Carlo Ossola; II: Un modello europeo, Roma, Bulzoni, 1980.

Parducci, Amos, Saggio sulla lirica di Juan Boscán, Bologna, Accademia delle Scienze dell'Istituto di Bologna, 1952.

Prieto, Antonio, La poesía española del siglo XVI, Madrid, Cátedra, 1984.

—, "La poesía de Garcilaso como cancionero", Homenaje a Manuel Alvar, to. III, Madrid, Gredos, 1986, 375-385.

Proyecto Boscán. Catálogo Histórico Crítico de las Traducciones de la Literatura Italiana al Castellano y al Catalán, coordinadores María de las Nieves Muñiz Muñiz y Cesáreo Calvo Rigual, <http://www.ub.es/boscan>

Quondam, Amedeo, "Questo povero cortegiano». Castiglione, il Libro, la Storia, Roma, Bulzoni, 2000. 
REA, Roberto, «Sul petrarchismo di Juan Boscán. La forma-canzoniere del Libro II nell'edizione del 1543 e il ms. Lastanosa-Gayangos», Studi romanzi, 3 (2007), 89-133.

Rico, Francisco, "De Garcilaso y otros petrarquismos», Revue de Littérature Comparée, 52 (1978), 325-338.

—, «A fianco di Garcilaso: poesia spagnola e poesia italiana nel primo Cinquecento", Studi petrarcheschi, 4 (1987), 229-236.

Riquer, Martín de, Juan Boscán y su cancionero barcelonés, Barcelona, Archivo Histórico Casa del Arcediano, 1945.

Ruiz Pérez, Pedro, Entre Narciso y Proteo: lírica y escritura de Garcilaso a Góngora, Vigo, Academia del Hispanismo, 2007.

—, La rúbrica del poeta: la expresión de la autoconciencia poética de Boscán a Góngora, Valladolid, Universidad de Valladolid, Secretariado de Publicaciones e Intercambio Editorial, 2009.

Segre, Cesare, «Problema e strutture nelle «Soledades» di A. Machado», I segni e la critica, Torino, Einaudi, 1969, 95-134. 
